\title{
Beyond Spectacular Specifics in the Study of Youth (Sub)Cultures
}

\section{Paul Hodkinson}

Journal of Youth Studies, Volume 15, Issue 5, 2012

(accepted, 1 Feb 2012 and available online via iFirst at the beginning of March 2012)

\begin{abstract}
This paper asks how much we can learn about youth music and style groupings from the detail of the spectacular content and practices which most obviously distinguish such groups. First, I consider an apparent revival in theoretically driven interpretations of subcultural style, music and content in recent work on the goth scene, arguing that, for all their sophistication, such studies seem liable to reproduce some of the difficulties of earlier studies of spectacular symbolic meanings unless their findings are connected with other kinds of evidence. The paper then examines recent calls for greater focus on the minutiae of participants' sensory experience of distinct subcultural practices. I discuss case studies of promising work in the area, while emphasising the need to avoid reducing subcultures to the specificities of selected spectacular experience. Drawing the two parts together, I suggest many elements of subcultures are neither imprinted in spectacular sounds and texts nor discernable from the immediate sensations spectacular practices give rise to. In order to enhance our overall understanding it is important, therefore, that our examination of the distinct and extraordinary features of subcultures is contextualised in relation to broader understandings a range of other properties and patterns which may be less distinct, unique or extraordinary.
\end{abstract}

\section{Keywords}

subculture, style, music, identity, youth, affect, meaning 


\section{Introduction}

Ever since the Centre for Contemporary Cultural Studies' (CCCS) theorised the stylistic significance of teddy boys, mods, skinheads and others, the question of what we can learn about distinctive music- and style-related youth cultures from the specifics of the spectacular cultural forms and practices on which they centre has remained a key consideration for those researching the subject. Whether in general public discourse or academic research, emphasis on what we might term the spectacular specifics of such groups continues often to be regarded as important. The largely textual and theoretical approach of the CCCS may often have been criticised, but interpretation of the symbolic meanings of the distinct music, style and other content around which subcultures cluster continues sometimes to be regarded as pivotal to understanding the significance of such groups. Meanwhile, particularly over the last decade or so, an increasing emphasis on the need to understand the distinct affective or sensual experiences given rise to by group-specific content or practices has placed a different sort of emphasis on spectacular specifics.

Such approaches tend to share the belief that, in order to get to the heart of understanding what youth-oriented music and style groupings are really about, investigations need to centre on the particular significance of the sets of cultural forms or practices that most strikingly or visibly differentiate such communities from one another and from the rest of society. Subcultures such as goth, punk, metal, skate and club cultures may share a variety of general social characteristics such as belonging, commitment, social patterns, status regimes and so on but what we really need to get to the bottom of, according to this view, are the specifics of why those particular styles emerged in a given time and context rather than others and what 
engagement with those particular sets of sounds and texts might tell us about the distinct orientation, meaning or significance of each group.

This article reflects critically on recent use of the analyses of spectacular specifics to make sense of music and style related communities. I place some emphasis here on the case study of the goth scene, a group on which I have previously carried out research of a general ethnographic nature (Hodkinson 2002) and I also refer, especially in the second half of the article, to studies of other groups. The first part of the paper examines recent attempts to examine the significance of the goth scene through theoretically driven textual analysis, something which, I argue, revives some features of the CCCS's focus on post-war spectacular style. I suggest that the theoretical decoding of subcultural meaning through textual analysis remains hazard-prone and would benefit from greater integration with broader understandings of the emergence of such groups and the lives and identities of participants.

Subsequently the focus shifts towards increasing calls for greater emphasis to be placed on the detail of participants' sensory experience of group-distinct content and practices. Drawing on recent examples from the study of popular music related experience in extreme metal culture and clubbing, I discuss the developing promise offered by such an approach, while stressing the need to avoid over-emphasising particular aspects of spectacular experience to the point that a broader sense of the motivations, identities and understandings that lie underneath such detail is obscured.

With respect to both textual and experiential approaches, I suggest that, if we over-privilege spectacular specifics as the primary focus for the analysis of youth cultural groups, we may 
underestimate features which are not discernable from the analysis of how the most distinctive features of subcultures look, sound or feel. Including general group-ideologies, identities, distinctions, hierarchies, networks and social motivations as well as a range of common cultural practices, these more general, 'content-neutral' features may sometimes be similar from one group to another. I conclude that, in order to develop a rounded understanding of such groups, we need to try to understand spectacular specifics in the context of these common features and, crucially, in relation to the elements of social ordinariness which underlie the spectacular.

\section{Spectacular Content}

At the outset I should perhaps declare an interest. My own ethnographic work on the goth scene has not focused, for the most part, on detailed analysis of the specifics of the group's style or music, placing greater attention on broader questions of identity, social patterns, commerce and media among other things (Hodkinson 2002). Nevertheless, it is not difficult to see why goth's distinctive features might be regarded as significant. An overall emphasis on dark imagery has predominated since the subculture's emergence in the early 1980s, whether through sinister musical tones and lyrics, the black hair and clothing of participants, or their ghostly white foundation and dark eyeliner. Goths often display tell-tale horror clichés, from crosses, to bats, to plastic fangs and such imagery can pervade lyrics too, not least Bauhaus' playful references to Bela Lugosi, star of the 1930s version of Dracula: 'Bela Lugosi's dead, undead, undead'. Such an apparent celebration of darkness, death and freakish, ostracised monsters (notably vampires) invites all manner of interpretation. 
The style is no less intriguing with respect to gender and sexuality. An emphasis on particular forms of femininity pervades both female and male goth style, with venerated males often exhibiting a slight build, make-up and tight and/or elegant clothes. There is also an emphasis on the sexually powerful figure of the dominatrix in female goth style, illustrated in the posture and appearance of influential figures such as Siouxsie Sioux and Patricia Morrison. In turn, this connects with a broader embrace of elements of fetish clothing and imagery for both sexes.

Bringing the two themes together, Carol Siegel combines the poststructuralist theory of Deleuze and Guttari with textual analysis of goth content to develop an explanation which characterises the subculture as a dark form of minoritarian resistance to the dominant values of conservative America (Siegel 2005). In addition to goth fashion, Siegel concentrates on examples of what are taken as goth-connected music, film and literature. The overt embrace of dark, sadomasochistic imagery and lyrics in Nine Inch Nails is emphasised, alongside the exploration of the trappings of conventional masculinity in The Cure, the gender fluidity and masochistic, bisexual goth heroes in the work of Poppy Brite, and examples of female sadism and power such as Angela Carter's 'Lady Purple'.

In the context of an American culture of mass consumption and conservative morality, the emphasis on darkness, horror, gender ambiguity and fetishism in goth content prompts an understanding of the subculture as 'a perversely eroticized embrace of death' (ibid. 7) centred upon 'the terrible beauty of the grotesque' (ibid. 166). Through embracing the imagery of the death, despair and deviance and combining it with hedonistic, unbounded forms of sexual pleasure, goth is deemed a subversive response to the restrictive capitalist society in which its participants grew up. The subculture is, Siegel argues, 'an alternative to the life-in-death that is 
the bland conformity demanded as the price of participation in American corporate culture' (ibid. 6). Goth, she suggests, 'appropriates the mainstream's designation of everything that does not fit into its systems of signification as dead or deathly' through the 'eroticization or even the simple valorisation of appearances and objects associated with morbidity and decay...' (ibid. 19).

While Siegel's analysis points to the post-structuralist resistance embodied by goths in the United States, a more recent analysis examines the significance of goth as a complex, contradictory and ironic expression of the post-communist context of youth in East Germany. Though less detailed than Siegel's book-length study, Isabella Van Elferen's research (2011) also foregrounds a theoretical interpretation of goth specifics, taking contemporary goth style, music and behaviour as a modern adaptation of the broader historical Gothic tradition and, therefore, an embodiment of theoretical themes associated with the latter, including the ghostly, the uncanny, the spectral, the ironic and the undead.

Van Elferen develops such themes into a carefully theorised assertion that goth expresses the liminal position of East German youth between the spectre of an 'undead' communist past and the unfulfilled desire of a failing consumerist future. The specifics of goth culture - and in particular its combined embrace, according to Van Elferen, of nostalgia, transgression, isolation, distrust in the future and irony - are taken as an ambivalent negotiation between extremes and a subtle, self-aware form of social criticism. Goths, she argues, 'actively embody the ghosts that appear in liminal spaces' (95) and being goth 'performs in self-aware irony the ambivalence between Marxist and capitalist spectrality that defines the undead German countries.' (101). 
Both Siegel and Van Elferen defend their largely textual approaches by arguing that the theorydriven examination of the specifics of goth offers a level of explanatory power and contextualisation inaccessible to ethnographic approaches centred on the detail of subjective lived experience. Siegel (2005: 19) suggests that the refusal of some such studies to engage with 'the symbolic messages conveyed' by goth and comparable subcultures reflects an overcautious approach unable to grasp the wider political significance of subcultures. Alongside the work of scholars such as Muggleton (2000), the avoidance of substantial analytic engagement with the specifics of goth content in my ethnographic study of subculture (Hodkinson 2002) is identified as an example here and Siegel points to a preoccupation with criticisms of the neoMarxist textual approach of the CCCS as an explanation for this reticence.

The argument that participant-oriented ethnographic research can sometimes be limited in its explanatory power and that the use of theory and the analysis of content have a part to play in subcultural analysis undoubtedly carry weight. Equally, there may be some justification for the claim that extensive criticism of the CCCS during the 1990 s and early 2000 s may have sometimes led to excessive avoidance of engagement with spectacular content in subcultural studies around this time, including my own. Nevertheless, the problems identified with the primarily theory-driven analysis of spectacular style carried out by most of the CCCS subcultural theorists were not imaginary ones and it is difficult not to see a replication of some of these in equally theory-driven and content-oriented work such as that of Siegel and Van Elferen.

It was the CCCS who pioneered the notion that the explanation for 'spectacular subcultures' was imprinted in the detail of clothes and cultural forms. Their carefully worked-through neoMarxist analysis suggests that teds, mods, skinheads and the rest should be understood as 
collective responses by working class youth to their subordinated and contradictory situation in a rapidly changing post-war UK society. For Phil Cohen (1973), each style offered a different 'magical' resolution to the fragmentation of traditional working class communities. Mods' embrace of an affluent appearance and hedonistic consumption articulated an upwardly mobile solution, while the skinheads' tough, masculine style embraced the 'lumpen' option. Clarke et al (1976) also match the detail of each style to elements of participants' socio-economic situation:

'Thus, in the expropriation and fetishisation of consumption and style itself, the 'Mods' cover for the gap between the never-ending-weekend and Monday's resumption of boring, dead-end work. Thus, in the resurrection of an archetypal and 'symbolic'... form of working class dress... skinheads reassert, but 'imaginarily' the values of a class, the essence of a style... to which few working-class adults any longer subscribe...' (Clarke et al 1976)

As well as being a 'magical' solution, subcultural style is specifically understood as symbolic resistance - a grassroots cultural challenge to hegemony through the transformation of everyday consumables, the development of subversive meanings and the winning of space. Though they focus on a different subculture in different social contexts, the studies of Siegel and Van Elferen in different ways also invoke this sense of the core distinct themes of goth content as resolving problems and articulating cultural resistance.

Although it is not always referred to or endorsed specifically, what often underlies the emphasis on style or content as the key to this problem-solving and/or resistance - whether in the CCCS accounts or those of Siegel and Van Elferen - is the principle of homology, which infers an 
inherent coherence between the different elements of each style, the behaviour and identities of participants and the broader significance of the group (Willis 1978). ${ }^{\text {ii }}$ Homology suggests nothing is accidental, random or coincidental - each element of the style is there for a reason and each contributes to a distinctive and coherent overall meaning. Whether implicit or explicit, it is this notion of an essential coherence between content, identity and meaning which often justifies the assumption that the content of music, clothes or other cultural forms holds the key to understanding subcultures.

Criticisms of the theoretical and content-oriented approach of the CCCS began as part of internal debates within the Birmingham School itself and have been regularly developed and recounted during the three decades since (e.g. Clarke 1981; Thornton 1995; Bennett 1999; Muggleton 2000). Our interest here is in those criticisms relating most directly to the CCCS' reliance on theoretical understandings of subcultural content. For, in spite of their sophistication in some respects, more recent theoretical studies of the specifics of style and content, including those of Siegel and Van Elferen on the goth scene, can find themselves subject to similar difficulties.

To begin with, the selection of a representative set of components to include in the analysis of subcultural content can be fraught with difficulties. Cohen, Hebdige and others are criticised by Gary Clarke (1981), for constructing frozen, idealised caricatures of mods, skinheads and others, inflating homological coherence and excluding elements which fit less neatly. The selection of cultural examples Siegel takes to be representative of goth is similarly open to question in some respects. Much is made - quite reasonably - of male gender ambiguity and sexual transgression in Nine Inch Nails, The Cure and others, for example, but little is said about the frequent use by 
various goth bands, promoters and others of apparently objectifying female imagery, for example (Brill 2008; Weinstock 2007). Siegel's analysis also places particular weight on a particular set of film and literary texts regarded, in one way or another, as goth-oriented. Here Siegel's approach, like that of Van Elferen, is heavily reliant on an assumed seamless coherence between the goth scene and the broader Gothic literary and cultural tradition.

Few would doubt that examples of Gothic literature, art and film are enjoyed by many goths and have influenced goth style and music more generally (Baddeley 2002). Yet such texts are also enjoyed by millions of other consumers, making their appropriateness as the primary vehicle to interpret the distinct meanings of the goth scene itself, questionable. More importantly, the broader Gothic tradition is responsible only for part of the look, sounds and texts of a subculture whose distinct style and music also incorporate numerous other influences, not least from a range of related music and youth cultural styles, including punk, metal, indie, new romantic, industrial and rave (Hodkinson 2007). Coming up with a definitive set of texts or influences through which a whole subculture might be interpreted arguably is an impossible task, but if content is to be selected and studied, we would do well to avoid focusing too quickly or exclusively on those elements which look or sound the most distinct or which fit best with linear explanations of influence or origin.

More fundamentally, there remain difficulties with reliance on the textual interpretations of theoretically-driven experts as a means to make sense of living, breathing social entities such as subcultures (Clarke 1981; Muggleton 2000). Whether in the 1970s or the 2000s it remains hard to determine whether such interpretations reveal more about the subculture itself or the theoretical persuasions of the analyst. We might note here that, according to English Literature- 
based scholar Catherine Spooner, the Gothic cultural tradition on which the analyses of both Siegel and Van Elferen centre has a particular tendency to be privileged as 'a site for whatever transgressive purposes the critic particularly subscribes to' (2004: 162). The point here is not that the use of existing theory or theoretical preconceptions should be replaced with some sort of purist version of inductive research. Rather, it is that subcultural amalgamations of style, music and cultural texts are open to a substantial range of understandings, many of which may be logical and plausible. The enduring difficulty is with how to judge one such interpretation against another, if not through the development of stronger connections between theoretical discussions of subcultural content and research relating to the empirical emergence, development and infrastructure of subcultures and, of course, the lived experiences of participants.

Without a degree of such grounding, theory-driven textual or stylistic accounts of the significance of subcultural groups continue sometimes to be presumptuous or dismissive when it comes to the relationship between their conclusions and insider interpretations. There is a tendency to assume either that the lived experiences of insiders are consistent with the interpretations of the analyst or that participants are ignorant of the true significance of their activities. Aware of the conundrum but unable to resolve it, Hebdige's position veers to and fro, in asserting, for example, that the semiotic guerrilla warfare he attributes to subcultures 'may be conducted at a level beneath the consciousness of the individual members' before adding '(though the subculture is still, at another level, an intentional communication)' (1979: 105).

In their more recent studies of goth, Van Elferen and Siegel take contrasting positions on the relationship between their analysis and the understandings of goths themselves. For Van 
Elferen, cultural groupings carry a significance liable to be invisible to insiders. To place too much emphasis on the understandings of the latter, she argues, is 'like asking an author what she intended with the book without investigating the book's position in its cultural, historical and intellectual surroundings' (2011: 94). Leaving aside the appropriateness of the author analogy, this particular formulation underplays the role of Van Elferen's selective theoretical reading of the 'text' itself (to use her terms) in determining a compelling but particular and narrow sense of the cultural, historical and intellectual origins and surroundings of goth in East Germany. While the account undoubtedly connects to some insider knowledge and experience on Van Elferen's part, as well as referring at times to elements of previous research, its core argument rests overwhelmingly on theoretically driven interpretations of the spectacular specifics of goth and the broader Gothic tradition it is assumed to embody.

In contrast to Van Elferen's emphasis on the need to transcend insider understandings through theoretical interpretation, Siegel asserts that goths would recognise themselves as depicted in her explanation of goth as an embodiment of a post-structuralist embrace of dark sexual and stylistic resistance. She asserts - rightly - that 'there is no intrinsic contrast between applying socalled high theory to subcultural artifacts as a means of understanding subcultures and attending respectfully to the ways participants in those cultures define themselves' (2007: 15). Yet, aside from some imprecise references to the agreement of 'goth acquaintances' with elements of her perspective, it remains unclear how her own theoretical explanation of the subculture squares with such insider understandings, which are largely peripheral to the account. What we are left with, as Spooner (2012) points out, is a set of textual interpretations which 'tends to conflate representations with the individuals represented'. 
Research which has been carried out on the lived experiences of goths does not bear out Siegel's claim about the coherence of participant understandings with her interpretations of the culture's apparent embrace of darkness and transgressive sexuality. Passionate though they were about the dark music, fashion and other cultural texts with which they identified, goths in my research frequently disagreed with one another as to their significance (Hodkinson 2002). Some read transgressive significance into their interest in horror and vampirism, though versions of what form the transgression took varied considerably. Most, however, claimed transgression only in the general sense of exhibiting cultural distinctiveness, authenticity and discerning taste. When it came to the specifics of their apparent embrace of darkness, I was repeatedly told that horror and certain other elements of Gothic culture were important influences and, sometimes, objects of fascination, but that the goth scene was primarily about passion for good music, style and fashion and not an expression of being depressed, satanic, revolutionary or pre-occupied by death. Indeed, in some cases, those deemed to take the latter themes too seriously were even pilloried, as here:

David: The vampires - you know, the ones that play Masquerade [vampire role-playing game] and so on and they dress up as goths and they have really bad horrendous make-up and so on and it invariably involves fake blood running down their faces and things like that - they turn up at goth clubs, and they fail to fit in completely, because they've completely missed the point. (Hodkinson 2002)

A more recent study of the UK and German goth scenes by Dunja Brill (2008) utilised an innovative combination of interviews, online observation and elements of the analysis of goth musical, stylistic and media content to identify a similarly contradictory picture with respect to 
goth, gender and sexuality. Brill confirms elements of Siegel's theoretical claims about sexual transgression, identifying a veneration by many goths of bisexuality and elements of fetishism, for example, as well as a broadly accepting atmosphere with respect to same-sex behaviour. Yet she goes on to show how same-sex behaviour was far more accepted in females than males, noting that androgynous-looking male goths frequently played up their heterosexuality through associating their appearance with traditional masculine qualities such as courage and the ability to have sex with attractive women. And female attractiveness, here, argues Brill, was constructed in a manner which emphasised an exaggerated version of heteronormative feminine attractiveness, something connected by Brill to her own textual analysis of prominent goth music, artwork, promotional posters and so on, some of which were clearly reliant upon sexually objectified versions of goth femininity.

My intention in drawing attention to this complex empirical picture is certainly not to deny any transgressive significance to the goth scene or to endorse an approach which excludes theory, criticism or the analysis of textual specifics. Rather, the point is that it remains difficult to know how to assess explanations of subcultural participants' identities whose core contentions seem largely disconnected from the lived experiences and subjective understandings of those participants, or the details of the emergence and workings of such groups. In particular, it remains important to question the unsubstantiated yet still prevalent assumption that subcultural participants amount to a sort of collective 'embodiment' of the content of the textual forms or themes with which they are associated - and hence of any broader meanings which we may assign to these. With particular respect to assertions of symbolic resistance, we would do well to heed Spooner's advice that, 'to enjoy a discourse of transgression... is not necessarily the same thing as being transgressive' (Spooner 2004: 165). 
Analysis of subcultural content does not have to be disconnected from other forms of evidence - and neither does the only alternative to overwhelmingly theory-driven interpretations have to be some sort of uncritical or theory-free endorsement of the minutiae of participant accounts. The words of participants can be compared and contrasted not only with one another, but with direct observation of their behaviour, with evidence about the broader orientation, development or impact of their subculture and with existing research and theory. If carefully contextualised in relation to a range of other evidence, the analysis of the themes and details of subcultural content may have much to offer as part of this. Brill's aforementioned multi-method study of gender transgression in the goth scene provides an instructive example of the potential value of such an integrated approach and, specifically, the ways in which analysis of distinctive content can be effectively integrated with a critical and theory-informed approach to participant-centred observation and analysis. And from a literary perspective, Catherine Spooner (2012) recently has offered some helpful indications of how, when each is regarded as partial and distinct set of representations and/or influences and understood in close relation to the lived histories and realities of the goth,scene, the analysis of texts most clearly associated with the culture may have the potential to contribute usefully to understandings. Perhaps such contextualised approaches, whether through multimethod individual projects or through connecting closely with knowledge generated by others, may help to garner the potential strengths of studying spectacular subcultural content without underplaying lived experiences.

\section{Spectacular Feeling and Emotion}

Contemporary studies which utilise semiology, musicology or other forms of textual analysis to interpret the meaning of subcultures revisit or develop a relatively familiar approach to the 
study of the spectacular specifics of subcultures. Recent years, however, have seen attempts to develop a rather different approach to the study of such specifics, one centred on the detail of the experiences that engagement with distinct subcultural forms and practices gives rise to. Put simply, this perspective calls for greater attention to be paid to the group-distinct elements of how subcultural practices feel, from the experience of listening to particular forms of music, to participating in distinct physical activities (dancing, skating, surfing), to adorning or modifying the body.

Proponents of the approach tend to identify a lack of attention to the specifics of subcultural experience in previous ethnographic studies. Ben Malbon, for example, suggests that Sarah Thornton's oft-cited study of club cultures offers useful discussion of things like the discursive establishment of boundaries, hierarchies and coolness, but 'largely neglects the experience of clubbing itself' and, in particular, the 'imaginative-emotional constitution of clubbing' (1999: 17). Similarly, Paul Sweetman (2009) argues that the 'particular pleasures' and affective experiences participants got from engaging with goth culture might have received more focus in my own aforementioned study of the subculture. David Hesmondhalgh (2007) concurs, pointing out that 'there is no real sense of why the goths liked the particular types of musics that they liked' and going on to ask 'how did musical darkness evoke emotions and identities in the private and collective lives of goths?' (Hesmondhalgh 2007: 44).

More generally, Malbon (1999), Sweetman (2001) and others suggest that, in paying insufficient attention to the specific experiential elements of subcultural practice, studies of subculture have omitted a core element of the significance of such groups. For Chris Driver (2011), the problem relates - in part - to an over-emphasis on subcultural consciousness, meaning and 
discourse and insufficient focus on the more immediate, direct and specific forms of emotional and bodily experience focused on by his own work on the Australian hardcore music scene. Arguments such as these have become particularly prominent in relation to the sensual significance of music and 'sonic worlds' as part of subcultures (Malbon 1999). As well as receiving attention in published work, lament for the comparative lack of attention to the specific forms of experience given rise to by distinct forms of music has figured at a number of recent seminars on the subject of subcultures.

Detailed ethnographic studies of the specifics of subcultural sensory experience have indeed been a little rare. In respect of music specifically, the most well-known and influential such study probably remains Paul Willis' examination of bike boys (Willis 1978). Combining ethnography with elements of musicological analysis, Willis describes how 'big beat' rock ' $n$ ' roll music was experienced by bike boys as a seamless expression of and complement to the other aspects of their subcultural identity, interactions and behaviour. The marginalisation of melody in the music and its domination by a 'driving, dancing rhythm', alongside the masculine posturing of artists such as Buddy and Elvis, were homologous, Willis contends, with a stopping, starting culture of the body centred on aggressive dancing and fast bike riding.

Willis' attention to the specific role of music listening experiences in bike boy identities has been rightly influential, but many regard the account as selective and over-simplified in its reduction of the subculture to its music. The boys clearly made links between their music and other aspects of life, but to infer from this that the whole subculture could be explained through the music's unique structure is some analytic leap. As Middleton (1990) shows, the explanation is not squared with the broader popularity of this music or its musicological overlaps with other 
styles disliked by the boys (Middleton 1990). Ultimately, the extent of the emphasis on experiences borne of distinct music as the centre point of a coherent meaning system risks negating Willis' ethnographic approach by implying that all that we need to know about bike boys was inscribed in distinct musical content after all.

Needless to say, the particular problems with Willis' pioneering study do not invalidate other attempts to understand the specifics of subcultural experience of music and other practices. Yet they might usefully draw attention to the need to ensure that an a priori focus on such minutiae does not result in the reduction of our overall understanding of subcultures to selected affective specifics, less still the detail of the distinct music or other forms of practice or substance that are deemed to give rise to such experiences.

In relation to the latter point, Sweetman (2001) acknowledges that although there had, by the time he was endorsing the approach, been a number of contributions to the analysis of subcultural experience, not least in relation to rave and dance culture (e.g. Stanley 1997; Reynolds 1997), few were centred on the accounts of fans themselves, with many reliant upon a combination of general observation, personal experience, theoretical speculation and/or direct analysis of music and other texts. This may reflect the difficulty of getting fans to articulate complex, intangible elements of emotion and sensation or the possibility that fans may differ among themselves with respect to the significance of such experience, as we saw earlier in the case of goths.

As part of his wide-ranging study of extreme metal, Keith Kahn-Harris' attempt to analyse respondent responses to questions about music listening experiences provides a useful 
illustration (2007). Kahn-Harris provides a valuable preliminary discussion of a variety of general respondent expressions of enjoyment of the music's aggression as a release of energy, an adrenaline rush or a form of emotional catharsis. Yet he claims he is unable to say too much more than this as a result of the reluctance of many participants to discuss their specific musicrelated motivations and experiences in greater detail and their 'ambivalence about the relationship between music, the self and the body' (2007: 54). One said to him 'It's hard to explain, I mean why do you like chocolate, why do you like coffee, you know? It's just a matter of taste' (ibid.).

Kahn-Harris rightly attributes such reluctance partly to the difficulty of articulating sensual experiences of music. Yet it is possible it also suggests that, beyond the broad feelings of passion, intensity and emotion that some of them described to him, participants may not have regarded the further minutiae of their sensual experiences of extreme metal as quite as unique or pivotal as we might expect. This does not mean distinct or extreme forms of experience ought not to be discounted - and it should be remembered that levels of both articulation and of experience may vary between individuals and groups. Nevertheless, there may be merit in Kahn-Harris' own suggestion that an understandable interest in the apparent extremity and uniqueness of subcultural (or 'scenic' as he prefers) music ought not to lead us to assume that distinct music communities are wholly defined by extra-ordinary experience.

A more recent study of extreme metal, by Nicola Allett (2010), used music elicitation in repeated interviews with a small group of participants to encourage discussion of music experience. The innovative approach enabled detailed discussion about music specifics, from the identification of rising and falling intensities and emotions in single tracks, to the evoking by 
music listening of individual past experiences or present moods to a broader emphasis reported by all respondents on the intensity of the general feelings that extreme metal could evoke in them. Nevertheless, Allett acknowledges that even her approach was not able fully to overcome the difficulties of vocalising the details of sensory experience. Meanwhile, it is not fully clear from her initial writing the broader importance of the details of such experience to the overall identities of metallers, or the extent to which their sensory experiences are unique to this genre or grouping. Allett usefully observes, consistent with other non-genre-specific studies (Denora 2000; Bull 2005), that music had close relationships with individual mood, connected to memories and enabled 'zoning out' amongst other things. The most collectively distinctive feature identified in the study appears to have been the level of emotion and 'intensity' of music listening experiences. The detail of this intensity may distinguish extreme metal fans from more casual music listeners, though the nature of their difference from participants of other committed music subcultures in this respect may benefit from further exploration. Allett's work can help develop our understanding of such questions and, in locating her music-focused analysis as part of a wider examination of subcultural identities, she demonstrates awareness of the limits as well as the benefits of the former.

Other studies, too, have gone some way towards integrating a detailed attention to the specifics of affect and experience into a more rounded understanding of particular groupings. Ben Malbon's work on clubbing provides a noteworthy earlier example (1999), in which theory is combined with extensive participant observation and respondent accounts to explore the micro-sociology of dancing in clubs with a particular emphasis on understanding the 'experiential consumption' at the heart of the scene. At the heart of this is the contention that, at the height of club nights, the combination of music, dancing, ecstasy and broader club 
environment can generate distinct forms of oceanic experience consisting of intense feelings of simultaneous transcendence, liminality, euphoria and release. The specifics of such affective moments lie at the heart of the group identity, playful transgression and vitality which characterise clubbing, argues Malbon, who situates his emphasis on spectacular affective experience within a broader outline of clubbing interactions and practices.

There do remain some uncertainties and questions. In spite of the broader context, the extent of the weight placed by Malbon on the affective particulars of the immediate sensory 'oceanic' experience sits a little uncomfortably with his candid acceptance at one point (112) that it is not fully clear how many of his eighteen respondents had experienced the set of oceanic sensations on which he focuses most prominently, or how often. Although some valuable and rich respondent quotations are provided, their variety and imprecision suggests Malbon's outline of the oceanic experience is - understandably - a little more theory-driven than are some of the other sections of the book. At the same time, for all its value there are also limits to how much the explanation can tell us. It shows, in some detail, that music is experienced on the dancefloor in a particularly intense fashion, that it can act as a powerful release, that dancers can both connect with collective euphoria and withdraw into internal moments of ecstasy, and so on. As in the case of Allet's study, it remains unclear how unique such intensities or releases are to the specifics of clubbing spaces or, more importantly, how possible it is, without the most extensive speculative/theoretical licence, to achieve the kind of detail that would distinguish between the sensory experience of, say, head banging extreme metallers, dancing clubbers or moshing straight-edgers. The depth, breadth and candour of Malbon's study has been valuable in provoking debate around such questions and in developing the contextualised study of affective experience, however. 
For while the study of immediate sensory experience as part of a broader understanding of subcultures is of substantial potential value, it is equally important to recognise the limits of what we can learn through such an emphasis, and, I would argue, to ensure that enthusiasm to study the affective and the sensual does not result in the reduction of subculture to the specifics of spectacular emotional or bodily experience. Just as there was more to being a bike boy than the immediate way dancing to Buddy Holly or engaging in fast bike riding made participants feel, there is more to extreme metal than the intense experiences given rise to by metal music and more to clubbing than the immediate sensations and emotions of the dance floor, important though they may be.

\section{Beyond Spectacular Specifics}

Whether in relation to the theoretical interpretation of spectacular content or the examination of particular elements of distinct subcultural experience, the challenge is to develop such approaches in such a way that they do not end up reducing the underlying significance of youth cultural groups to the looks, sounds, texts and practices which make them most obviously, unique or extra-ordinary. There are, after all, countless aspects to subcultural life which are not discernable from the study of unique content or bodily experience and which may not be entirely group-distinctive or even particularly spectacular. Including the complex sets of social and institutional processes through which such groups emerge, expand and recede as well as the range of individual and group motivations, values, norms, discourses and everyday practices that surround them, the 'content-neutral' aspects of goth, punk, club scenes and other such 
groups can be strikingly similar - and may also illuminate elements of ordinariness to apparently spectacular identities and lifestyles.

As with Brill's multifaceted examination of the goth scene, the strength of Kahn-Harris' aforementioned study of extreme metal is the placing of its discussion of metal music and of the experiences it gave rise to within a broader appreciation of a range of other participant practices, priorities and experiences and a careful analysis of the infrastructure of promoters, organisers, media and commerce that enabled the scene to function. As well as helping illuminate the various particular social facets of one scene or another, the employment of this sort of approach enables the identification of common characteristics and explanatory factors between apparently contrasting groups.

Comparisons of non-content-specific aspects of goths, metallers, punks, clubbers skaters and others, for example, are liable to reveal marked similarities with respect to the values and group ideologies espoused by participants and their practices of identification and distinction. Discursive espousals, for example, of distinctiveness, creativity, authenticity, self expression and open-mindedness, alongside disavowals of a perceived trend-following, undiscerning and commercialised dominant culture, have been reported and deconstructed by a host of studies of different groups in different times and spaces, as have the connections between such distinctions and the establishment of internal hierarchies and external boundary drawing, to take another example (e.g. Thornton 1995; Hodkinson 2002; Kahn-Harris 2007; Brill 2008; Hannerz 2010 to name a few). Specific elements of the music, style or ideologies to which such values and judgements are attached may be distinct to each group, but the nature and operation of the broader distinctions, hierarchies and identities to which these give rise appear 
to be strikingly similar between one subculture and another. Identifying the nature and extent of such connections and similarities is every bit as important as the development of explanations of more group-distinctive content or experience.

Numerous other similarities can be identified between subcultural groups, of course, from the kinds of institutional and social processes through which they often emerge, to the essential activities, experiences and motivations which lie at their heart and their relationship - in practice and perception - with media and commerce. At the most basic level it is worth remembering that most music and style related subcultures involve activities such as listening to music, dressing in a distinctive manner, shopping, collecting, hanging out in clubs, bars or outdoor spaces, watching or playing in bands, dancing, flirting and dating. When asked about the meaning and significance of her subcultural participation, one of my goth respondents put it in the following way:

Sarah: 'It's about dressing up in your best stuff - socialising and making new friends and listening to great music' (Hodkinson 2002).

Such activities may take on striking or even spectacular formats, of course, and may take on differential intensity, emphasis and significance in each case, but are unlikely to be entirely distinct or unique. Goths may dress and dance in different ways from others, may listen to different sorts of music. Yet there remain key elements to their enjoyment of and identification with such activities which are comparable to their equivalents in the case of punks, metallers, garage fans, northern soul participants and, to some degree at least, a range of more casual clubbers. 
This brings us onto a further point - that, for all their unusualness in some respects, aspects of subcultural motivation, practice, understanding and identity connect to broader equivalents across so-called 'normal' or 'mainstream' society. Thornton (1995) shows, for example, that the drawing of boundaries and hierarchies of identity and status by clubbers (which have been found to operate in a similar manner in other subcultural groups) replicated key elements of Bourdieu's description (1984) of the operation of bourgeois cultural distinctions across society. We might add that specific espousals of self-expression, independent creativity and so on identifiable in myriad subcultures draw upon ideologies of authenticity associated for decades with rock music in its general sense, and of course with still- broader understandings of artistic aura (Frith 1981).

Turning to everyday subcultural practices, the centrality of the avid consumption and collection of cultural goods not only provides common ground between subcultures but indicates a further connection to practices, meanings and understandings across consumer-societies, many of which are explicated usefully in the study of consumption and everyday life (Miles 1998; Bennett 2005). As Kahn-Harris (2007) argues, we ought not to lose sight of the various aspects of ordinariness to participation in apparently spectacular communities. In my research on goths, a further example of such ordinariness was the pointed emphasis in respondent accounts and my observations on socialising and friendships as activities and motivating factors of the utmost importance. For all the significance of the spectacular aesthetics, meanings and experiences of goth style, it was social contact, alongside the general sense of belonging to which it was connected, which seemed most pivotal to becoming and remaining involved (Hodkinson 2002). 
Such observations may provoke questions about the very conceptual distinctiveness of the kinds of groups which tend to be studied by researchers of scenes or subcultures. Some may ask whether, given the presence of so many common or ordinary practices and motivations, there is any benefit in separating groups such as goths and punks from other communities across society that are involved in consuming, collecting, socialising and sharing an identity (Sweetman 2009). The question is a good one - and worthy of more detailed consideration than I have space for here. It may be that there are more similarities between goths and model railway enthusiasts, or between straight-edgers and avid fans of Star Trek than is sometimes assumed, and such a possibility warrants careful investigation.

Yet the importance of studying common and ordinary dimensions to outwardly spectacular youth cultures does not mean that more unique aspects of subcultural content, ideas or practices should be regarded as unimportant. At the very least, subcultural friendships, consumption, collecting, dancing and so on remain extra-ordinary in their location within the parameters and environment of unusually concentrated and often defiant communities centred on sets of styles and practices which, in some respects, are spectacular and distinctive and are understood as such both by insiders and outsiders. Neither are my comments here intended to preclude the careful, contextualised identification and elaboration of distinct forms of cultural or political transgression and resistance. With this in mind, it is understanding the ways in which apparently common motivations and practices manifest themselves through extraordinary content, practices, experiences, levels of commitment and so on - and vice versa - which perhaps offers the most fruitful path to the ongoing development of our understanding of such phenomena. 


\section{Conclusion}

In this article I have tried to focus a critical lens on the premise - sometimes stated, sometimes not - that in order to understand and explain youth subcultures we must focus detailed attention on their spectacular specifics. First, I examined an apparent resurgence in the use of theoretical interpretations of spectacular content by focusing on some recent examinations of the goth scene. I suggested that the focus of these replicated some of the difficulties of the CCCS' textual approach of the 1970s, particularly in their apparent homological assumption that subcultures are embodiments of the bodies of content around which they coalesce. I went on to discuss the recent popularity of calls for researchers to focus greater attention on the distinct and spectacular affective experience of subcultural practices such as music listening, dancing, body modification and so on. I sought to place emphasis on the possible value of such an approach while at the same time emphasising the limits to how much it can tell us about subcultures and, specifically, the importance of ensuring that the significance of such groups does not end up being reduced to the specifics of certain spectacular practices.

In the final section I have suggested that some of the core aspects of the motivations, meanings and workings of subcultures are liable to remain hidden if the spectacular specifics of content and affective experience are over-prioritised in our methodologies or explanations. As well as being unable to identify the importance of crucial social and institutional features, I have suggested that if we focus too narrowly on the detail of style, music, film and/or of the emotional or physical responses they evoke, we may over-estimate the conceptual distinctiveness of each subculture and insufficiently explore their similarities with one another, less still the ways they each draw upon wider social practices, discourses and values. Looking 
forward, then, I have suggested that one of the challenges for researchers in this area is to place greater - and explicit - emphasis on the relationship between commonalities between groupings and more unique elements to each, as well as on the interplay in all such groups between the ordinary and the spectacular. During the course of this article, I have examined some studies which, through placing the study of spectacular content and/or experience within the context of a broader appreciation of the emergence, workings, identities and understandings of such groups, have gone some way towards such synthesis.

\section{References}

Allett, N. (2010), 'Sounding Out: Using Music Elicitation in Qualitative Research', Realities Working Papers, 14, URL:

http://www.socialsciences.manchester.ac.uk/realities/publications/workingpapers/14-2010-03realities-music-elicitation.pdf

Baddeley, G. (2002), Goth Chic: A Connoisseur's Guide To Dark Culture. London: Plexus.

Bennett, A. (1999) 'Subcultures or Neo-Tribes? Rethinking the Relationship Between Youth, Style and Musical Taste', Sociology, 33 (3).

Bennett, A. (2005) Culture and Everyday Life, London: Sage.

Bourdieu, P. (1984), Distinction: A Social Critique of the Judgement of Taste, London: Routledge.

Brill, D. (2008), Goth Culture: Gender, Sexuality and Style, Oxford: Berg.

Bull, M. (2005), 'No Dead Air! The iPod and the Culture of Mobile Listening', Leisure Studies 24 (4).

Clarke, G. (1981) 'Defending Ski-Jumpers: A Critique of Theories of Youth Subcultures', in S. Frith and A. Goodwin (eds) (1990) On Record: Rock, Pop and the Written Word, London: Routledge.

Clarke, J., Hall, S., Jefferson, T. and Roberts, B. (1976) 'Subcultures, Cultures and Class: a Theoretical Overview', in S. Hall and T. Jefferson (eds) Resistance Through Rituals: Youth Subcultures in Post War Britain, London: Hutchinson.

Cohen, P. (1972) 'Sub-cultural Conflict and Working Class Community', Working Papers in Cultural Studies. No.2. 
Denora, T. (2000), Music in Everyday Life, Cambridge University Press.

Driver, C. (2011), 'Thick Spaces, Temporal Bodies: Habitus-Linking in 'Subcultural' Places', unpublished conference paper, Youth Subcultures in Changing Societies, Tallin University.

Frith, S. (1981), 'The Magic That Can Set You Free: The Ideology of Folk and the Myth of the Rock Community', Popular Music, 1: 159-68.

Haenfler, R. (2009), Straight Edge: Clean-Living Youth, Hardcore Punk and Social Change, Rutgers University Press.

Hannerz, E. (2010), 'Mainstream versus Punk Subcultures', unpublished conference paper, Youth 2010: Identities, Transitions, Cultures, University of Surrey.

Hebdige, D. (1976), 'The Meaning of Mod', in S. Hall and T. Jefferson (eds) Resistance Through Rituals: Youth Subcultures in Post War Britain, London: Hutchinson.

Hebdige, D. (1979), Subculture. The Meaning of Style, London: Routledge.

Hesmondhalgh, D. (2007), 'Recent Concepts in Youth Cultural Studies: Critical Reflections From the Sociology of Music' in Hodkinson, P. and Deicke, W. (eds.), Youth Cultures: Scenes, Subcultures and Tribes, New York: Routledge.

Hodkinson, P. (2002) Goth. Identity, Style and Subculture, Oxford: Berg.

Hodkinson, P. (2007) 'Gothic Music and Subculture', in Spooner, C. and McEvoy, E. (eds.), The Routledge Companion to Gothic, London: Routledge.

Kahn-Harris, K. (2007), Extreme Metal: Music and Culture on the Edge, Oxford: Berg.

Malbon, B. (1999), Clubbing: Dancing, Ecstasy and Vitality, London: Routledge.

Miles, S. (1998), Consumerism, as a Way of Life, London: Sage.

Muggleton, D. (2000), Inside Subculture: The Postmodern Meaning of Style, Oxford: Berg.

Reynolds, S. (1997), 'Rave Culture: Living Dream or Living Death?' in Redhead, S. (ed.), The Club Cultures Reader, Oxford: Blackwell.

Siegel, C. (2006), Goth's Dark Empire, Indianapolis: Indianna University Press.

Spooner, C. (2004), Fashioning Goth Bodies, Manchester: Manchester University Press.

Spooner, C. (2012), 'Goth Culture', in Punter, D. (ed.) A New Companion to the Gothic, Chichester: Wiley-Blackwell. 
Stanley, C. (1997), 'Not Drowning but Waving: Urban Narratives of Dissent in the Wild Zone', in Redhead, S. (ed.), The Club Cultures Reader, Oxford: Blackwell.

Sweetman, P. (2001), 'Stop Making Sense? The Problem of the Body in Youth/Sub/CounterCulture', in Cunningham-Burley, S. and Backett-Milburn, K. (eds.), Exploring the Body, Basingstoke: Palgrave.

Sweetman, P. (2009), 'Subculture: Hodkinson's Goth' in Devine, F. and Heath, S. (eds.), Doing Social Science: Evidence and Methods in Empirical Research, London: Palgrave.

Thornton, S. (1995), Club Cultures: Music, Media and Subcultural Capital, Cambridge: Polity Press.

Van Elferen, I. (2011), 'East German Goth and the Spectres of Marx', Popular Music 30 (1): 89103.

Weinstock, J. (2007), "Gothic Fetishism', in Goodlad, L. and Bibbley, M. (eds.), Goth: Undead Subculture, Durham: Duke University Press.

Willis, P. (1978), Profane Culture, London: Routledge and Kegan Paul.

\footnotetext{
' For the sake of simplicity, I use the notion of subculture here to refer to distinct communities centred on style, music and certain other texts and practices. I recognise that debate persists on the conceptualisation of such groups, but hope readers will understand the desire to leave these particular arguments to one side here. music, style and other forms of cultural artefact or activity.
} 